\title{
Dynamic Monitoring of Rubber Asphalt Production Quality Based on HOPLS
}

\author{
Renfeng Yang ${ }^{1}$, Haichao $\mathrm{An}^{2 *}$ and Wei Yuan ${ }^{3}$ \\ ${ }^{1,2,3}$ School of Construction Machinery, Chang'an University, Xi'an 710064, China \\ 1913297715@qq.com,2*290065476@qq.com,31069810100@qq.com
}

\begin{abstract}
To achieve the real-time monitoring and process control of the rubber asphalt production quality. The mathematical model of the relationship between the rubber asphalt production quality and its production process key control parameters is established based on the higher order partial least squares (HOPLS). And relying on the entity project, the rubber asphalt performance indicators are predicted. At the same time, the dynamic quality control range of key parameters is proposed by statistically analyzing the large data. The comparison of rubber asphalt performance before and after monitoring shows that the predicted value is basically identical with that in laboratory. When the model is used to monitor rubber asphalt production process and the control parameters are within the dynamic quality control range, the rubber asphalt performance fluctuates smoothly and is improved than that before monitoring. Furthermore, the $180^{\circ} \mathrm{C}$ Haake viscosity is increased by $20.8 \%$, the softening point is raised by $8 \%$, the $25^{\circ} \mathrm{C}$ cone penetration is reduced by $4 \%$, the springback recovery is improved by $3 \%$, the $5^{\circ} \mathrm{C}$ low temperature ductility has a $13.8 \%$ increase.
\end{abstract}

Keywords: Road engineering; rubber asphalt; dynamic monitoring; HOPLS; key control parameters

\section{Introduction}

To promote recycling of waste tires, reduce the construction cost and improve the road performance, the rubber asphalt is widely used in high-grade highways [1-2]. In recent years, in order to improve the rubber asphalt production quality, more and more attention is paid to the rubber asphalt production process parameters affecting its performance. For instance, the processing temperature, storage time and storage mode are analyzed in [3], but the key parameter such as the powder dosage is ignored. The influence of high temperature and storage time on rubber asphalt segregation degree is researched [4]. The relationship between shear time, shear temperature, sulfur content and the rubber asphalt performance indicators is studied in [5].

As is known in [6], the reaction time and the developmental temperature have important implications for the rubber asphalt performance indicators based on DSR and GPC methods. It is reported that with the powder dosage increasing, the rubber asphalt temperature sensitivity is getting steadily worse based on Brookfield viscosity in [7-8].

However, the existing research of these problems is mostly based on subsequent offline inspection in laboratory, which not only takes a long time but also can not avoid the large losses caused by the unqualified rubber asphalt production. If the warning information about rubber asphalt production parameters fluctuation is provided early, some effective measures can be taken in production and the rubber asphalt performance will be guaranteed. In recent years, the process monitoring based on multi-way principal

Received (December 15, 2016), Review Result (September 28, 2017), Accepted (October 3, 2017)

${ }^{*}$ Corresponding Author 
component analysis (MPCA) [9] and multi-way partial least squares (MPLS) [10-12] has been widely used in industrial process modeling analysis. However, the two methods are still the linear analysis, which will produce larger prediction error for complex batch process, and it is proved by experiments in [13]. Therefore, in this paper, the key control parameters model in rubber asphalt production is established based on the high order partial least squares (HOPLS) [14-15] and the characteristics of rubber asphalt production process. 3D production data is decomposed into orthogonal tucker matrix by the model, which is solved out by using higher order singular value decomposition, higher-order orthogonal iteration and tensor decomposition. This method overcomes the drawback of losing data information in the MPCA and MPLS analysis methods and it is verified based on rubber asphalt performance testing before and after monitoring in the end. The dynamic quality control range of the key parameters is obtained based on the statistical analysis, which provides a certain reference for achieving the rubber asphalt production process quality control and improving the rubber asphalt performance.

\section{Work Principle of Rubber Asphalt Production Equipment}

The work principle of the rubber asphalt production equipment is shown in Figure 1. Matrix asphalt is raised its temperature to $190{ }^{\circ} \mathrm{C}$ by using a two-stage heat exchanger (rapid heating) in a short time. Then it is pumped into the stirred tank with high-speed mixing blades through the flowmeter. At the same time, the required amount of rubber powder is computed based on the blending ratio of the rubber powder and asphalt matrix provided by the laboratory. Then the rubber powder is conveyed to the stirred tank by feeding screw and measurement screw. When the rubber powder and asphalt matrix are intermingled for 10 minutes in stirred tank with high speed stirring and high temperature, they are pumped to the developmental tank and there is a 45-minute development process. In order to match the production capacity of asphalt mixing equipment, there are usually 4 developmental tanks with a capacity of 20 tons.

When the first developmental tank finishing feeding, then the second, the third and the fourth developmental tank will be used. Once development is complete, the rubber asphalt can be directly pumped to the asphalt mixing equipment when required.

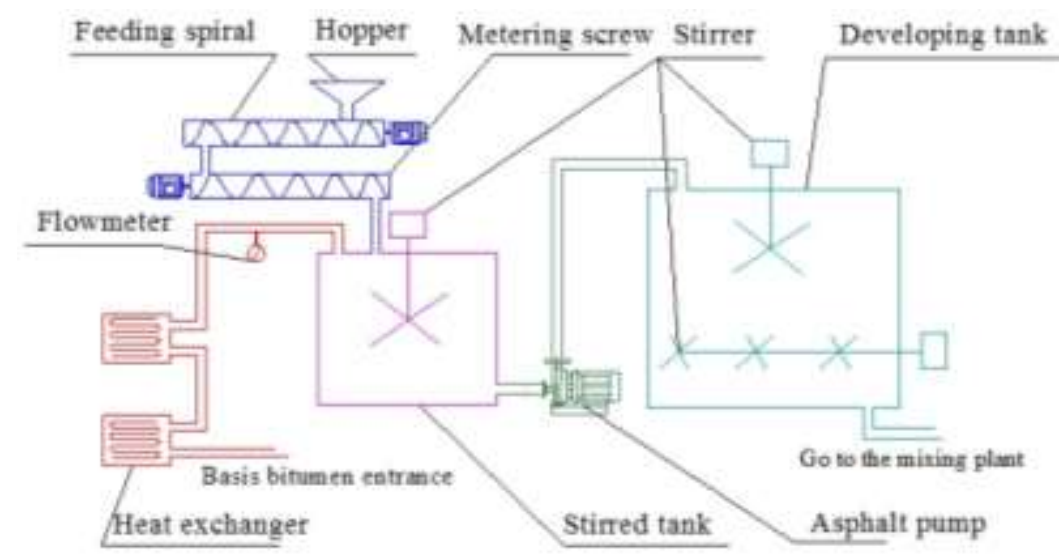

\section{Figure1. Work Flow Chart of Rubber Asphalt Production Equipment}

\section{Rubber Asphalt Production Process Model Based on HOPLS}

There will be of great significance for dynamically monitoring the key control parameters of rubber asphalt production process [16]. Usually, the rubber asphalt production quality is closely related to the process parameters. However, the rubber asphalt equipment with no unified national standards, is designed by the enterprises 
themselves, which has some deficiencies now. Such as the key control parameter instrument is obviously nonlinear at high temperature, which causes great errors; There is not associated control between the measurement of the rubber powder and matrix asphalt, and the blending ratio is difficult to real-time control in production; So far, there is not effective method to detect the powder content in laboratory [14]. The existing control system can not store the production data in production, which can not provide effectively correction for subsequent production. These existing problems will affect the rubber asphalt production quality.

The rubber asphalt production process can be described as a three dimensional control parameters array $X(N \times I \times J)$ and two-dimensional performance mass matrix $Y(N \times K)$. Because the rubber asphalt production equipment is intermittent, the three dimensional array $X(N \times I \times J)$ is generated from the control parameter data from the $\mathrm{N}$ production batch $N(\mathrm{n}=1, \cdots, \mathrm{N})$ is the production batch on the day, $I(\mathrm{i}=1, \cdots, \mathrm{I})$ is the number of the control parameters, and $\mathrm{J}$ is the number of collected sample of all the control parameters in a batch. After development completion, various performance indicators need to be detected in laboratory and each indicator data is recorded as the two-dimensional matrix $Y(N \times K)$.

Based on the characteristics of $X$ and $Y, X$ can be decomposed into the sum of tensor with the rank $\left(1, \mathrm{~L}_{1}, \mathrm{~L}_{2}\right)$, and $Y$ is decomposed into the sum of a set of matrix, whose number of latent vector is $R$.

$$
\begin{aligned}
& X=\sum_{\mathrm{r}=1}^{R} G_{r} \times{ }_{1} t_{r} \times{ }_{2} P_{r}^{(1)} \times{ }_{3} P_{r}^{(2)}+E_{R} \\
& Y=\sum_{r=1}^{R} u_{r} q_{r}^{T}+F_{R}
\end{aligned}
$$

Where the symbol "×" is the modular multiplication, $G_{r}$ is a nuclear tensor, $t_{\mathrm{r}} \in I R^{I_{1}}$ is the rth latent vector, $\left\{P_{\mathrm{r}}^{(\mathrm{n})}\right\}_{\mathrm{n}=1}^{N-1} \in I R^{I_{n+1} \times L_{n+1}}$ and $q_{r}$ are the load matrix along the mode-n and mode-m, $\mathrm{u}_{r}$ is the score matrix of $Y, E_{R}$ and $F_{R}$ are the residual, $\square q_{r} \square=1$, $\square t_{r} \sqcap=1$, and $P_{r}^{(\mathrm{n}){ }^{\mathrm{T}}} P_{r}^{(\mathrm{n})}=I$. Like the traditional partial least squares, we assume that the latent vector $t_{\mathrm{r}}$ and $u_{\mathrm{r}}$ exist a certain linear relationship. $U=T D+Z$, where $D$ is the diagonal matrix, and $Z$ is the gaussian residual, we can get

$$
Y=T D Q^{T}+F_{R}^{*}=\sum_{r=1}^{R} d_{r} t_{r} q_{r}^{T}+F_{R}^{*}
$$

By computation, we find that when $u=Y q$, the minimum value in $\square Y-u q^{T} \square_{F}^{2}$ can be obtained. Considering the $u, t$ and nuclear tensor $G$, we find that working out $P^{(\mathrm{n})}$ and $\mathrm{q}$ is equivalent to optimize the formula 3 .

$$
\begin{aligned}
& \max _{\left\{P^{(\mathrm{n})}, \mathrm{q}\right\}} \square X \times{ }_{1} Y^{T} \times{ }_{1} \mathrm{q}^{T} \times{ }_{1} P^{(1) T} \times{ }_{3} P^{(2) T} \square_{F}^{2}, \\
& \text { s.t. } P^{(\mathrm{n}) T} P^{(\mathrm{n})}=I, \square q \square_{F}=1
\end{aligned}
$$

For the formula 3 , there is a cross covariance tensor $C=X \times{ }_{1} Y^{T} . P^{(\mathrm{n})}$ and q can be obtained by using high order Orthogonal iteration, and the nuclear tensor $G^{(\mathrm{C})}$ is also worked out. When the above parameters are obtained, decomposing $\mathrm{X}$ along mode- 1 can get

$$
X_{(1)}=t G_{(1)}\left(\mathrm{P}^{(2) \mathrm{T}} \otimes \mathrm{P}^{1)}\right)^{\mathrm{T}}+\mathrm{E}_{(1)}
$$

Where $G_{(1)} \in I R^{1 \times L_{2} L_{3}}$ can be obtained by the linear features of the nuclear tensor $G$ and $G^{(\mathrm{C})}, G^{(\mathrm{C})}=\mathrm{d} G$, and $\mathrm{t}$ is solved out by the formula5. 


$$
\begin{aligned}
& \mathrm{t}=\left(\mathrm{X} \times{ }_{2} \mathrm{P}^{(1) \mathrm{T}} \times \cdots \times{ }_{N} \mathrm{P}^{(\mathrm{N}-1) \mathrm{T}}\right)_{(1)} G_{(1)}^{(\mathrm{C})+}, \\
& \mathrm{t}=t / \square t \square_{F}
\end{aligned}
$$

where $P^{(n)}$ is a list of orthogonal matrix, and "+" is the generalized inverse. So we can find the regression coefficient of $Y$.

$$
d=t^{T} \mathrm{u}=\mathrm{t}^{T} Y q
$$

In consideration of the above situation, the model based on the high order partial least squares and rubber asphalt production process statistical data is established as follows:

First of all, $X$ and $Y$ are defined, $X \in I R^{I_{1} \times I_{2} \times I_{3}} ; Y \in I R^{I_{1} \times M}$,then they are initialized. We can get $E_{1}=X, \mathrm{~F}_{1}=Y$ and $r=1$.

1) $C_{r}=E_{\mathrm{r}} \times{ }_{1} \mathrm{~F}_{r}^{T}$

2) $C_{r}$ is solved out by higher-order orthogonal iteration based on the rank $\left(1, \mathrm{~L}_{2}, \mathrm{~L}_{3}\right)$, and we can get

$$
\begin{aligned}
& C_{r} \approx G_{\mathrm{r}}^{(\mathrm{C})} \times{ }_{1} q_{r} \times{ }_{2} P_{r}^{(1)} \times{ }_{3} P_{r}^{(2)}, \\
& \mathrm{t}_{r}=\left(\mathrm{E}_{\mathrm{C}} \times{ }_{2} P_{r}^{(1)} \times{ }_{3} P_{r}^{(2)}\right){ }_{(1)}\left(\operatorname{vec}^{\mathrm{T}}\left(G_{\mathrm{r}}^{(\mathrm{C})}\right)\right)^{+}
\end{aligned}
$$

Where vec is used to transfer $G_{\mathrm{r}}^{(\mathrm{C})}$ to the vector form of $1 \times\left(\mathrm{L}_{2} \times \mathrm{L}_{3}\right)$.

$$
\begin{aligned}
& t_{r}=\frac{t_{r}}{\square t_{r} \square}, \\
& G_{r}=\sqcap E_{r} ; \quad t_{r}^{\mathrm{T}}, P_{r}^{(1) \mathrm{T}}, P_{r}^{(2) \mathrm{T}} \sqcap, \\
& \mathrm{u}_{r}=F_{r} q_{r}, \\
& d_{r}=\mathrm{u}_{r}{ }^{T} t_{r}
\end{aligned}
$$

3) If $r=R$ or $\square E_{\mathrm{r}} \square_{F}<\varepsilon, \square F_{\mathrm{r}} \square_{F}<\varepsilon$, we can get

$$
\left\{P_{r}^{(1)}, P_{r}^{(2)}\right\} ; \mathrm{Q} ;\left\{G_{\mathrm{r}}\right\} ; D ; T \text {. }
$$

4) if $E_{r}=E_{r}-\square G_{r} ; t_{r}^{\mathrm{T}}, P_{r}^{(1) \mathrm{T}}, P_{r}^{(2) \mathrm{T}} \square, \mathrm{F}_{\mathrm{r}}=\mathrm{F}_{\mathrm{r}}-d_{r} t_{r} q_{r}^{T}$ and $r=r+1$, we return the formula 1. Otherwise we can get

$$
\left\{P_{r}^{(1)}, P_{r}^{(2)}\right\} ; \mathrm{Q} ;\left\{G_{\mathrm{r}}\right\} ; D ; T \text {. }
$$

In the next production batch, the obtained data is marked as $X^{\prime}$, and the new output is calculated by $G_{r}, P_{r}^{(1)}, P_{r}^{(2)}$ and the latent vector $T^{\prime}, Q_{\mathrm{r}}^{(\mathrm{m})}$ and $D_{\mathrm{r}}$. At the same time, we can get

$$
\hat{Y}^{\prime} \approx T^{\prime} Q^{* T}=X_{(1)}^{\prime} W Q^{* T}
$$

Where $W$ and $Q^{*}$ are obtained by the formula 13 .

$$
\begin{aligned}
& w_{r}=\left(\mathrm{P}_{\mathrm{r}}^{(2)} \otimes \mathrm{P}_{\mathrm{r}}^{(1)}\right) \mathrm{G}_{(1)}^{+} \\
& \mathrm{q}_{r}^{*}=D_{r(1)}\left(\mathrm{Q}^{(2)} \otimes Q_{\mathrm{r}}^{(1)}\right)^{T}
\end{aligned}
$$

In consideration of the above formula, it is concluded that the predicted value of $Y$ is as follows:

$$
Y^{\prime} \approx X_{(1)}^{\prime} W D Q^{T}
$$

Where $D$ is the orthogonal array with the element $d_{\mathrm{r}}$, and the rth row of the $Q$ matrix is consists of $\mathrm{q}_{r}(r=1, \cdots, R)$. The model based on the high order partial least squares and rubber asphalt production data not only avoids the destruction of data structure caused by the traditional partial least squares, but also achieves the dynamic monitoring of the 
rubber asphalt production process, which effectively ensures the rubber asphalt production quality.

\section{Dynamic Monitoring of Rubber Asphalt Production Process Based on HOPLS}

\subsection{Dynamic Monitoring Realization of Rubber Asphalt Key Control Parameters}

The dynamic monitoring implementation of the rubber asphalt production process can provide a certain help for the rubber asphalt quality control. Rubber asphalt has broad prospects in severe cold region, however, the unstable production quality restricts its widespread application. Therefore, in this paper, with the pavement maintenance project of expressway in Hebei province as the support and based on the wireless data-acquisition instrument of the key control parameters developed by a company, the model based on HOPLS is imported into the backend server. One day, the rubber asphalt equipment produced 14 batches, and the pumping time of rubber powder and matrix asphalt was about 50 minutes. The rubber asphalt developmental time in single batch was about 45 minutes, but the longest can not exceed 2 hours. The data was collected at 20s intervals. With the rubber powder amount, asphalt amount, premixed temperature, developmental

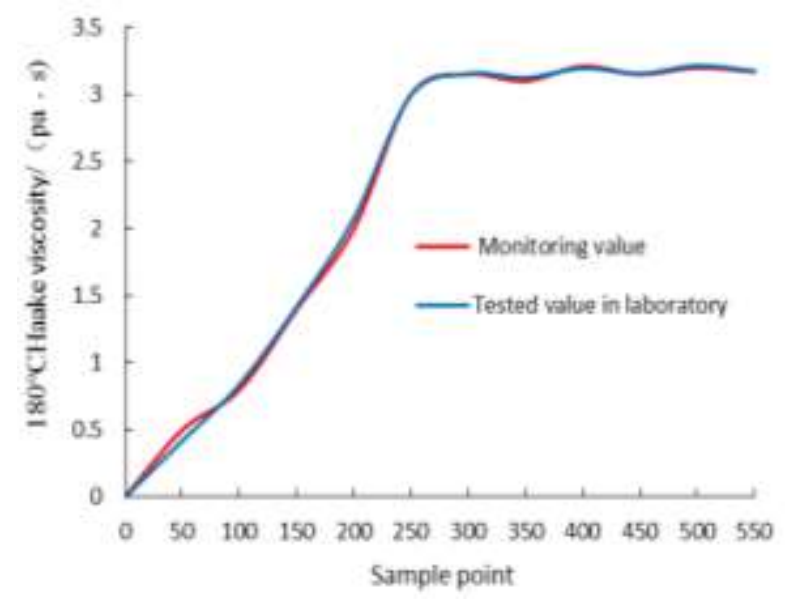

Figure 2. Haake Viscosity Monitoring Value Compared With the Actual Value

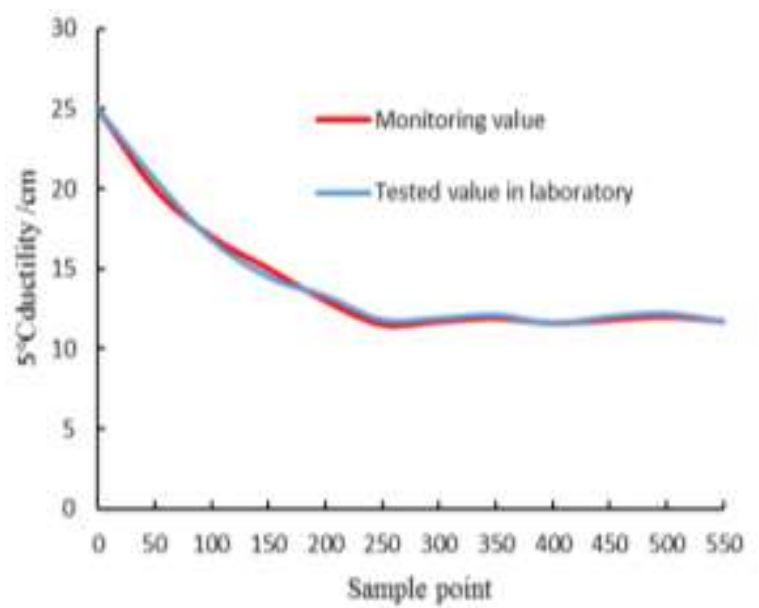

Figure 3. $5{ }^{\circ} \mathrm{C}$ Ductility Monitoring Value Compared With the Actual Value

temperature, stirring speed, and developmental time as independent variables and with the $180{ }^{\circ} \mathrm{C}$ Haake viscosity and the $5{ }^{\circ} \mathrm{C}$ low temperature ductility as dependent variables, the 
tensor $\mathrm{X}(14 \times 6 \times 510$; batch $\times$ variable $\times$ sample $)$ and the matrix $Y_{a}(14 \times 510)$ and $Y_{\mathrm{b}}$

$(14 \times 510)$ are generated. In other word, the regression model of the $180{ }^{\circ} \mathrm{C}$ Haake viscosity and $5{ }^{\circ} \mathrm{C}$ low temperature ductility is obtained. The forecasting results and actual values in laboratory are compared, which is shown in figure 2 and figure 3.

In general, the model is able to achieve good prediction for the rubber asphalt production quality. The figure 2 and figure 3 shows that in the initial production, the matrix asphalt is pumped firstly, so the $180{ }^{\circ} \mathrm{C}$ Haake viscosity value is relatively low and the $5{ }^{\circ} \mathrm{C}$ low temperature ductility value is relatively high. With the rubber powder amount increasing, the $180{ }^{\circ} \mathrm{C}$ Haake viscosity value increases and the $5{ }^{\circ} \mathrm{C}$ low temperature ductility value reduces. In general, before the 280 sample points, there are some errors for the two indicators between the monitoring values and the values in laboratory. At the same time, the corresponding developmental time is less than 45 minutes. However, after the 280 sample points, the monitoring values are basicly consistent with that in laboratory, and it has played a good prediction effect. The rubber asphalt is usually used only after 45 -minute development, so the errors before the 280 sample points can be ignored.

\subsection{Control Range of Key Control Parameters Dynamic Quality of Rubber Asphalt}

At present, the rubber asphalt production quality is monitored and tested mainly based on sampling inspection in laboratory. Compared with the number of samples in the large-scale construction of the highway, it is still insufficient in laboratory, which cannot fully reflect the rubber asphalt performance [17-18]. Relying on the data acquisition and analysis of the construction process of multiple rubber asphalt highway in Shaanxi and Hebei province and the test results the results of rubber asphalt in laboratory, the fluctuation range of the key production parameters is obtained, which is shown in table 1. During the rubber asphalt production process, all the key production parameters should be in this range. Once one of the parameters goes out of scope, the system will timely remind operators to take effective measures to modify them, which realizes the rubber asphalt quality control and avoids great losses caused by unqualified production.

Table 1. Dynamic Quality Control Range

\begin{tabular}{|l|c|}
\hline Statistical indicator & Allowable deviation \\
\hline Rubber powder dynamic content / \% & $\pm 0.5 \%$ \\
\hline Dynamic mixing temperature / ${ }^{\circ} \mathrm{C}$ & \pm 5 \\
\hline Dynamic developmental temperature / ${ }^{\circ} \mathrm{C}$ & \pm 5 \\
\hline Effective developmental time / min & $45 \sim 120$ \\
\hline
\end{tabular}

\section{Test Verification}

In order to verify the control effects of the monitoring model based on HOPLS and dynamic quality control range, the test of the performance indexes of a bulk-production rubber asphalt on different dates before and after monitoring is carried out. First the 90 \# matrix asphalt provided by Sinopec and the 30 mesh rubber powder (physical and chemical properties are shown in table 2) produced by Zhongxuan in xi'an are chose for experiment research.

Table 2. Physical and Chemical Composition Test Results of Rubber Powder 


\begin{tabular}{|l|c|c|}
\hline Test item & $\begin{array}{l}\text { Technical } \\
\text { requirements }\end{array}$ & Testing result \\
\hline Moisture content/\% & $<1$ & 0.62 \\
\hline Acetone extract $/ \%$ & $\leq 22$ & 6.10 \\
\hline Metal content $/ \%$ & $<0.05$ & 0 \\
\hline Fiber content $/ \%$ & $<1$ & 0.01 \\
\hline Rubber hydrocarbon content $/ \%$ & $\geq 42$ & 61 \\
\hline Carbon black content /\% & $\geq 28$ & 28 \\
\hline Ash content /\% & $\leq 8$ & 8 \\
\hline Natural rubber qualitative analysis & $/$ & Natural rubber \\
\hline
\end{tabular}

When the powder content is $20 \%$, developmental temperature is $185{ }^{\circ} \mathrm{C}$ and developmental time is 60 minutes, the performance indicators of a bulk-production rubber asphalt such as $180{ }^{\circ} \mathrm{CHaake}$ viscosity, $25{ }^{\circ} \mathrm{C}$ cone penetration, softening point, springback recovery and $5{ }^{\circ} \mathrm{C}$ low temperature ductility are detected before and after monitoring. The test results are shown in Figure 4, 5, 6, 7 and 8.

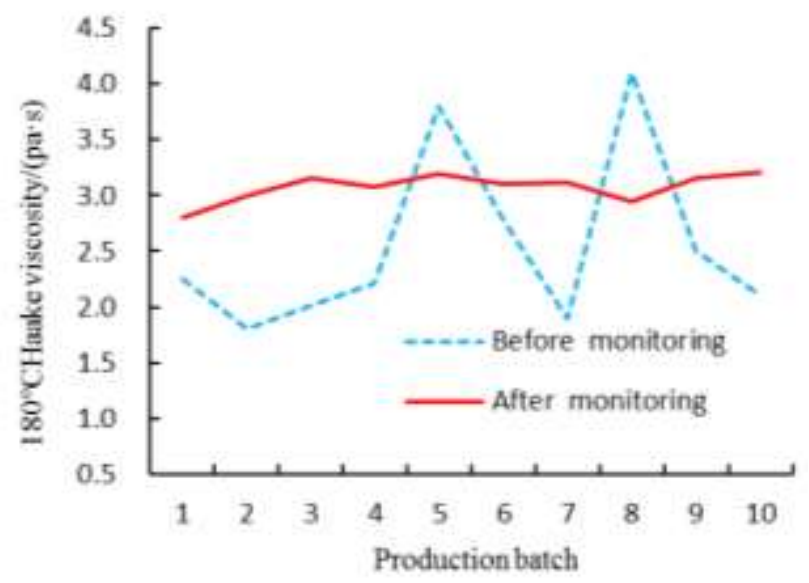

Figure 4. Rubber Asphalt Haake Viscosity Curve

Compared with before monitoring, the $180^{\circ} \mathrm{C}$ Haake viscosity fluctuates in the smooth and is mostly in $2.8 \sim 3.2 \mathrm{~Pa} \cdot \mathrm{s}$, which will contribute to improve the performance of rubber asphalt mixture. Besides, with the same test materials, test parameters and mixing ratio, the $180^{\circ} \mathrm{C}$ Haake viscosity in laboratory is $3.15 \mathrm{~Pa} \cdot \mathrm{s}$ (technical specification for $1.5 \sim 4.0$ $\mathrm{Pa} \cdot \mathrm{s}$ ), which can not only satisfy the wrapped and caking property requirements for stone, but also will not lead rubber asphalt to be pumped and compacted difficultly. However, in figure 4 , the minimum of $180{ }^{\circ} \mathrm{C}$ Haake viscosity before monitoring is only $1.8 \mathrm{~Pa} \cdot \mathrm{s}$ and the maximum is $4.1 \mathrm{~Pa} \cdot \mathrm{s}$, whose fluctuation is bigger than that after monitoring. Although sometimes it can reach $2.79 \mathrm{~Pa} \cdot \mathrm{s}$, the probability appeared is still lower. This seems to be because the mixing ratio has changed during the production process due to the rubber asphalt powder cluster, weighing, and conveying. Furthermore, we fail to discover and adjust the situation in time. After monitoring, once we find that the fluctuations of key control parameters exceed the permitted range, the operations can take effectively measures to modify them. So the $180{ }^{\circ} \mathrm{C}$ Haake viscosity fluctuates in the smooth, which is raised by about $20.8 \%$ compared with that before monitoring. At the same time, it also meets the requirements of construction workability. 


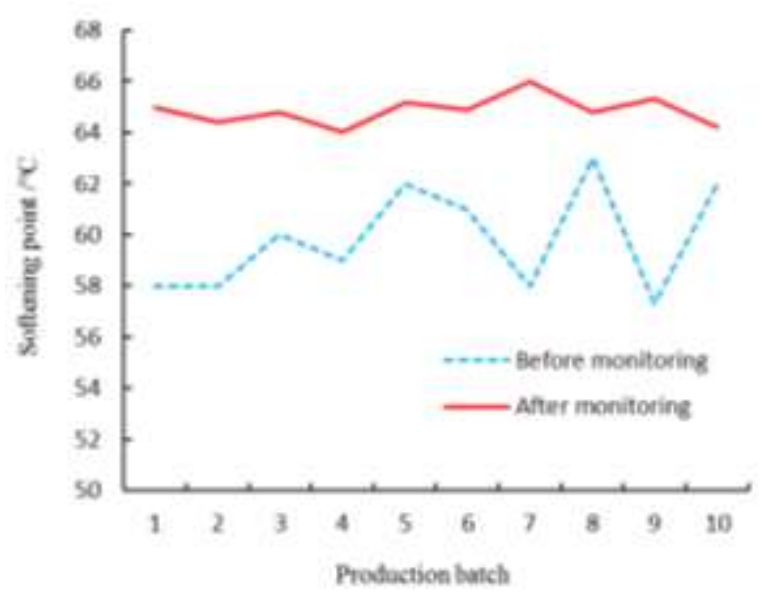

Figure 5. Rubber Asphalt Softening Point Curve

In Figure 5, after dynamic monitoring, the softening point is $64 \sim 66{ }^{\circ} \mathrm{C}$, which is consistent with the standard test in laboratory. Besides its fluctuation range is plus or minus $2{ }^{\circ} \mathrm{C}$ and it meets well the construction technical requirement. However, the fluctuation of softening point indicator before monitoring is large, and the average value is lower than that after monitoring. The difference between the maximum and minimum value reaches $8{ }^{\circ} \mathrm{C}$, and part of the test value is lower than the technical specification requirements $\left(60{ }^{\circ} \mathrm{C}\right)$, which is related to that the control of rubber powder content and developmental temperature has a large fluctuations. With the amount of rubber powder reducing, the solid-liquid system of the rubber asphalt can not present more solid phase characteristics. The large fluctuations of developmental temperature is against rubber powder evenly spreading and the formation of space network structure. Furthermore, the average value of the softening point after monitoring is increased by about $8 \%$ than that before monitoring.

In figure 6, compared with before monitoring, there has been a significant improvement in the fluctuation of the cone penetration after dynamic monitoring. The cone penetration is relatively small and fluctuates smoothly, which will contribute to improve the cohesive force of rubber asphalt increases. Usually the main influence factor of rubber asphalt

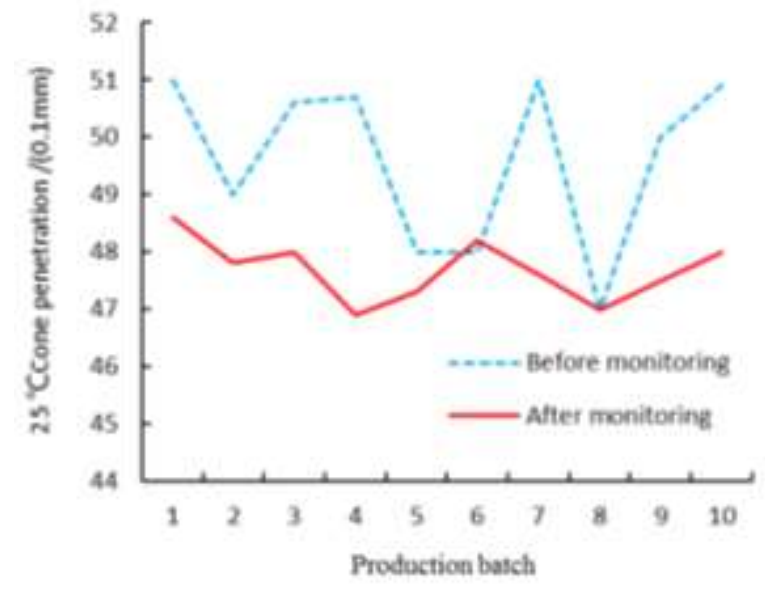

Figure 6. Rubber Asphalt $25{ }^{\circ} \mathrm{C}$ Cone Penetration Curve

$25{ }^{\circ} \mathrm{C}$ cone penetration is the powder content, and with it increasing, $25{ }^{\circ} \mathrm{C}$ cone penetration reduces. In figure 6 , the curve before monitoring is obvious fluctuation. In other word, the powder mixing ratio is not stable during the production process, and if 
there is no dynamic monitoring, it is hard for the operator to find it in time. Therefore, the wrapped performance of rubber asphalt for aggregates will get worse and the service life and the service quality of highway will also be affected seriously. In addition, you can also find out from Figure 6 the average value after monitoring is decreased by about $4 \%$ than that before monitoring.

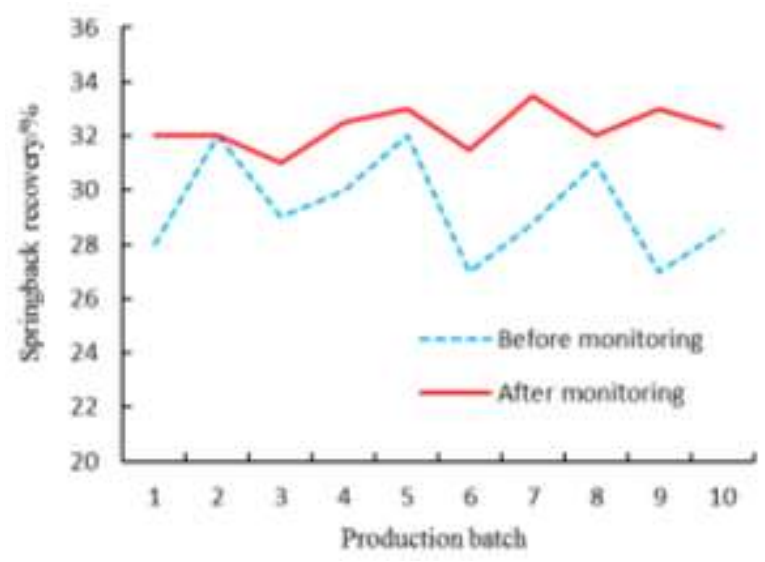

\section{Figure 7. Rubber Asphalt Springback Recovery Curve}

With dynamic monitoring, each process parameters is controlled within the prescribed range, thus the springback recovery value is relatively stable and is basically in $32 \sim 34 \%$. It is consistent with the standard test value in laboratory and it is of great significance to improve the low temperature performance of rubber asphalt. Usually with the springback recovery performance of rubber asphalt improved, the compressive resilience of rubber asphalt mixture is also enhanced. In particular, it is extremely beneficial to eliminate the thin layer of ice on the roads in the severe cold area. However, in Figure 7, there are large fluctuations for the springback recovery value before monitoring, which is mostly below $30 \%$. It is decreased 3\% than the standard test value in laboratory and obviously this is not good for the improvement of rubber asphalt. Analysis reveals that the cause of this phenomenon may be that the large fluctuation of production parameters and the untimely adjustment result in the uneven distribution of rubber powder.

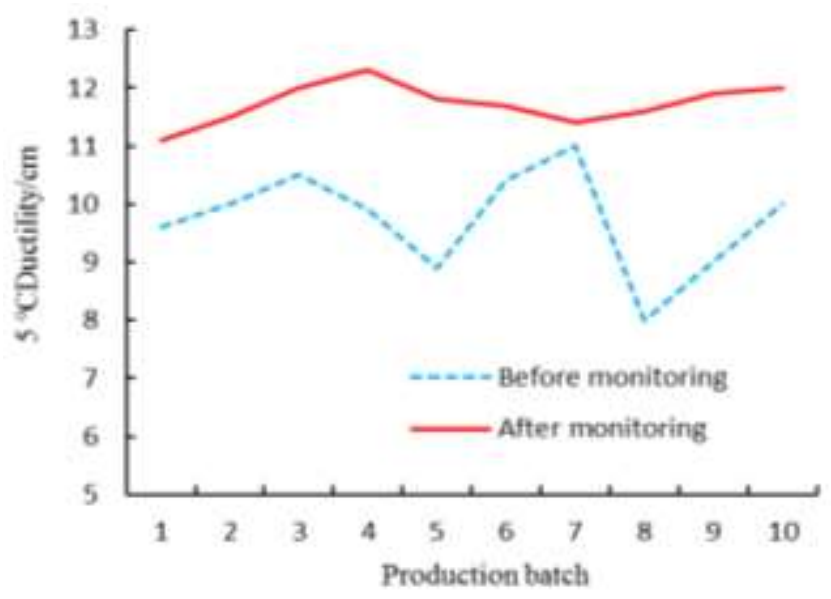

Figure $8.5{ }^{\circ} \mathrm{C}$ Rubber Asphalt Ductility Curve

When the various production process parameters are within the dynamic quality control range, the ductility indicator fluctuates smoothly and is equal with the standard values in laboratory. The low temperature ductility is closely associated with the road performance 
of the rubber asphalt mixture, especially with the low temperature cracking performance. The greater ductility is, the effect of resistance to low temperature deformation is more obvious. In figure 8 , however, the $5{ }^{\circ} \mathrm{C}$ low temperature ductility value fluctuates significantly before monitoring and it is also lower than $11.6 \mathrm{~cm}$ in laboratory, whic has to do with the instability of production parameters. After the dynamic monitoring has been applied, the average value of the $5{ }^{\circ} \mathrm{C}$ low temperature ductility is increased by about $13.8 \%$ and it reaches the demand of the engineering construction.

\section{Conclusion}

1) The mathematical model of the relationship between the rubber asphalt production quality and the key control parameters such as the amount of rubber powder and matrix asphalt, premixed temperature, developmental temperature, stirring speed, developmental time is established based on HOPLS. Simulation results show that the predicted values of various performance indicators are basically identical with that in laboratory, which provides a certain help for rubber asphalt production process control and adjustment, and also gives some references for other modified asphalt quality control.

2) The dynamic quality control range of the key control parameters is put forward based on the HOPLS model and big data analysis

3) Analysis and experiment results of rubber asphalt performance show that after dynamic monitoring, the various performance indicators fluctuate smoothly and the average values are improved. Among them, the $180^{\circ} \mathrm{C}$ Haake viscosity is increased by $20.8 \%$, the softening point is raised by $8 \%, 25^{\circ} \mathrm{C}$ cone penetration is reduced by $4 \%$, the springback recovery performance is improved by $3 \%, 5{ }^{\circ} \mathrm{C}$ low temperature ductility has a $13.8 \%$ increase.

\section{Acknowledgments}

This work is supported in part by the Central University Basic Scientific Research Special Funding Project (NO. 310825152101) and the Hebei Provincial Transport Department Funding Project (NO. Y-20150217).

\section{Reference}

[1] X. Y. Li, L. Ping, H.N. Wang, C. Zhang and Z. P. You. "Performance test of rubber asphalt based on domestic and abroad test methods", Journal of Traffic and Transportation Engineering, vol. 15, no. 2, (2015), pp. 10-16

[2] W. Hong, Q. S. Li, G. Q. Guan, J. Liu, J. Sun, and G. Z. Xing. "Pavement performance and application of anion rubber-modified asphalt", Chinese Science Bulletin, vol. 57, no. 18, (2012), pp. 2323-2328.

[3] Y. Q. Liu, J. Li, C. X. Li and S. Han. "Influence analysis of processing parameters on the rubber modified asphalt properties". Journal of Highway and Transportation Research and development (Application Edition), vol. 4, (2015), pp.163-165.

[4] L. He, X. M. Huang, Y. Ma, D. X. Zhuang and T. Ma. "Experimental study on storage stability of crumb rubber modified asphalt", Journal of Southeast University (Natural Science Edition), vol. 41, no. 5, (2011), pp.1086-1091.

[5] L. P. He, A. Q. Shen, C. Xie and L. P. Liu. "Orthogonal test for rubber asphalt properties", Journal of Chang'an University (Natural Science Edition), vol. 34, no. 1, (2014), pp.7-12.

[6] K. D. Jeong, S. J. Lee, S. N. Amirkhanian and K. W. Kim. "Interaction effects of crumb rubber modified asphalt binders", Construction and Building Materials, vol. 24, no. 5, (2010), pp. 824-831.

[7] F. J. Navarro, P. Partal, A. F. Martinezboza and C. Gallegos. "Influence of crumb rubber concentration on the rheological behavior of a crumb rubber modified bitumen", Energy and Fuels, vol. 19, no. 5, (2005), pp. 1984-1990.

[8] M. Mamlouk and B. Mobasher. "Cracking resistance of asphalt rubber mix versus hot-mix asphalt", Road Materials and Pavement Design, vol. 5, no. 4, (2004), pp. 435-451.

[9] R. Roopwani, Z. Shi and I. S. Buckner. "Application of principal component analysis (PCA) to evaluating the deformation behaviors of pharmaceutical powders", Journal of Pharmaceutical Innovation, vol. 8, no. 2, (2004), pp. 121-130. 
[10] J. Wu, W. Luo, X. Wang, Q. Cheng, C. Sun and H. Li, "A new application of WT-ANN method to control the preparation process of met form in hydrochloride tablets by near infrared spectroscopy compared to PLS", Journal of Pharmceutical and Biomedical Analysis, vol. 80, no. 3, (2013), pp. 186-191.

[11] G. Gins. J. Vanlaer and J. F. M. V. Impe, "Discriminating between critical and noncritical disturbances in (Bio) chemical bach processes using multi-model fault detection and end-quality prediction", Industrial and Engineering Chemistry Research, vol. 51, no. 38, (2012), pp. 12375-12385.

[12] T. Naes, O. Tomic, N. K. Afseth, V. Segtnan and I. Mage, "Multi-block regression based on combination so for thogonalisation, PLS regressionand canonical correlation analysis", Chemometrics and Intelligent Laboratory Systems, vol. 124, no. 9, (2013), pp. 32-42.

[13] Y. J. Wang, M. X. Jia and Z. Z. Mao. "Weak fault monitoring method for batch process based on multi-model SDKPCA", Chemometrics and Intelligent Laboratroy Systems, vol. 118, no. 118, (2012), pp. 1-12.

[14] L. Luo, S. Bao and Z. Gao. "Quality prediction based on HOPLS-CP for batch processes", Chemometrics and Intelligent Laboratory Systems, vol. 143, no. 4, (2015), pp. 28-39.

[15] Q. Zhao, C. F. Caiafa, D. P. Mandic, Z. C. Chao, Y. Nagasaka, N. Fujii, L. Zhang and A. Cichocki. "Higher order partial least squares (HOPLS): a generalized multilinear regression method", IEEE Transactions on Software Engineering, vol. 35, no. 7, (2013), pp. 1660-73.

[16] P. Chang, P. Wang and X. J. Gao. "Batch ocess monitoring for microbial fermentation based on multi-way kernel entropy component analysis", Journal of Chemical Engineering of Chinese Universities, vol. 29, no. 2, (2015), pp. 395-399.

[17] D. Y. Niu, S. Han, K. Chen and O. M. Xu. "Study of influence of key process parameters on SBS modified asphalt", Journal of Chang'an University (Natural Science Edition), vol. 34, no. 3, (2014), pp. 7-16.

[18] W. Hou, "Experimental study on impact of production process parameters on rubber asphalt performance", Applied Mechanics and Materials, vol. 204-208, no. 10, (2012), pp. 3629-3633.

\section{Authors}

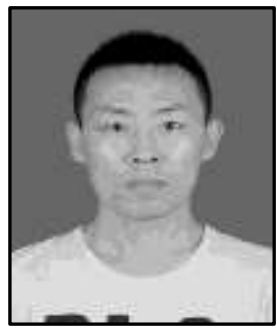

Haichao An, he was born in Hebei Province, China, in 1985. He is currently pursuing the PH.D.degree in the School of Construction Machinery of Chang'an University, Xi'an, China. His research interests include engineering machinery theory and work quality control.

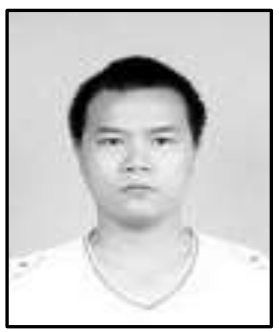

Wei Yuan, he was born in Henan Province, China, in 1992. He is currently pursuing the M.S. degree in the School of Construction Machinery of Chang'an University, Xi'an, China. His research interests include engineering machinery theory and work quality control.

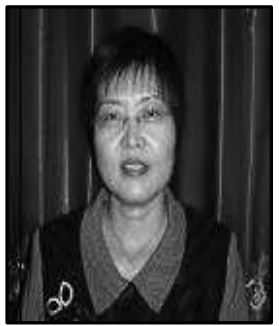

Renfeng Yang, she was born in Shaanxi Province, China, in 1960. She has been a Professor at Chang'an University, and she is the author of one book, more than 50articles, and more than 8 inventions. Her research is in the area of engineering machinery theory and work quality control; dynamic quality monitoring technology in highway construction process and highway network monitoring and control technology. Her research products on construction machinery control are widely used in engineering construction. 
International Journal of Control and Automation

Vol. 10, No. 11 (2017) 